Volume 1, Number 2, July 2019

\title{
Review article \\ Collection, preservation and forwarding of biological samples for toxicological analysis in medico legal autopsy cases
}

\author{
Utpal Kumar Biswas, ${ }^{1}$ Nashid Tabassum Khan, ${ }^{2}$ Mohammad Ahad Hossain, Abdul Kader ${ }^{4}$
}

\begin{abstract}
Collection of proper autopsy specimen is an essential step in the process of toxicology case work. Improper collection of these specimens can greatly alter or negate chemical and toxicological analysis. This article is an update about the standard methods of biological specimen collection procedures for toxicological analysis which will be helpful for the forensic pathologist and forensicscientists. ${ }^{1}$
\end{abstract}

Keywords: Sampling, preservation, body fluids, poison, tissues.

\section{Introduction}

In handling the Medico legal autopsy cases, certain standard guidelines are necessary to be laid down to assist in the selection of appropriate specimens of the body fluids and tissue for postmortem biochemical and toxicological analysis. After death there is a rapid change in the cellular level biochemistry due to autolysis. The drugs and other poisons may be released from the binding sites in tissues and major organs. The unabsorbed drug may diffuse fromstomach; care should be taken in selection of blood and tissue sampling sites. Many a times the autopsy is conducted before all the circumstantial evidences are collected and investigated. Hence, it is vital to preserve all the necessary samples at the time of autopsy. Ideally the samples for toxicological or biochemical analysis should be collected before the postmortem. However, it may not be possible for all the samples and there maybe difficulty in sampling without opening the body.

\section{Biological fluids}

\section{Blood}

In all medico legal investigation cases blood specimen should be obtained when blood is available. It is used as a reference sample for identification in unidentified cases and also for toxicological analysis. Peripheral blood concentration has been shown to be more reliable for toxicological analysis than the conventional heart blood. Therefore, in all suspected poisoning deaths or in all cases of unknown causes of death a femoral blood specimen should be collected. Before autopsy it can be collected by inserting the needle at about two finger breadths below the inguinal ligament at middle point marked between the anterior superior iliac spine and the symphysis. But it is best obtained by puncturing the femoral vein using a 30 $\mathrm{ml}$ syringe with wide bore needle after exposing the vein by dissection and clamping or ligating it proximal to the collection site.

Usually $20 \mathrm{ml}$ of blood ${ }^{4}$ is sufficient and it has to be preserved in sodium fluoride of $10 \mathrm{mg} / \mathrm{ml}$ and potassium oxalate, $30 \mathrm{mg} / 10 \mathrm{ml}$ of blood concentration in a fresh wide mouthed glass container of $30 \mathrm{ml}$ with screw cap 1 (universal container). The glass container should be made of amber glass to inhibit photo degeneration. The rubber or cork caps should be avoided. Sodium fluoride should be avoided. Sodium fluoride protects blood from postmortem changes such as bacterial production of ethanol or other alcohols. It also helps to protect other labile drugs such as cocaine, nitrazepam and clonazepam from degradation ${ }^{4}$. The most satisfactory way of obtaining a venous blood sample is venipuncture of the femoral vein by direct puncture in the groin before the autopsy begins.

\section{Urine}

Urine specimen is of great value even in small amount especially in screening of unknown drug or poison, particularly substance of abuse since the concentrations are generally higher than in blood and a number of metabolites may also be present. Urine specimen is also valuable in the quantitative analysis of alcohol, where there is uncertainty over the validity of a blood specimen. Before conducting the autopsy, urine can be collected

1. Assistant Professor, Department of Forensic Medicine, Monowara Sikder Medical College,

2. Associate Professor Department of Forensic Medicine, Z H Sikder Women's Medical college,

3. Assistant Professor, Department of Forensic Medicine, Dhaka Central International Medical college,

4. Lecturer, Department of Forensic Medicine, Z H Sikder Women's Medical college

Address of correspondence:

Dr. Utpal Kumar Biswas. Assistant Professor, Department of Forensic medicine, Monowara Sikder Medical College. e-mail: utpalbiswas2009@gmail.com 
by catheter or suprapubic puncture with $5-10 \mathrm{ml}$ syringe and needle (22 gauge 3 inch). With the body in supine position, palpate the bladder and identify the insertion site at midline and $2 \mathrm{~cm}$ cephalad to the pubic bone. At the insertion site, introduce the 22 gauge 3 inch needle attached to the $10 \mathrm{ml}$ syringe. Direct the needle caudad (the bladder is a peritoneal organ in adults) at a $10^{\circ}$ to $20^{\circ}$ angle from the perpendicular at midline. Gently aspirate while introducing the needle. If no urine is aspirated, withdraw the needle to the subcutaneous space and readvance in a slightly different direction, $10^{\circ}$ caudad or cephalad and aspirate again. But it can be best obtained during autopsy after exposing the abdomen by puncturing the fundus of the bladder with syringe and needle. It has to be preserved in sodium fluoride $(10 \mathrm{mg} / \mathrm{ml})$ in a $30 \mathrm{ml}$ glass container with a screw cap. A sample of $20 \mathrm{ml}$ is sufficient for toxicological analysis.

\section{Bile}

Bile is helpful in estimating the drugs, which are concentrated by liver and excreted into the gall bladder like opiates and acetaminophen (paracetamol). It is not routinely preserved, but only in selected cases. It is preserved in $30 \mathrm{ml}$ glass screw capped container. A 20 $\mathrm{ml}$ of bile is adequate for toxicological analysis. It can be collected directly by incising the gall bladder into a glass bottle. It is a viscous fluid, which makes it difficult to be sucked by needle and syringe.

\section{Vitreous Humor}

The vitreous humor specimen is particularly useful for alcohols or in diabetes and insulin related deaths. It is also very useful where the body has decomposed. The fluid in the eye resists putrefaction longer than other body fluids as it is sterile and remains well protected in eye. It is useful for certain biochemical tests such as urea, creatinine, glucose, lactose and alcohol. Vitreous humor must be collected from both eyes in separate vials of 10 $\mathrm{ml}$. It is preserved with sodium fluoride $(10 \mathrm{mg} / \mathrm{ml})$. A puncture should be made through the sclera at the outer canthus with a fine 19 gauge needle in $5 \mathrm{ml}$ syringe. It should be placed laterally as far as possible, pulling the lid out, so that when released, it returns to cover of the puncture mark for cosmetic reasons. The sclera should be punctured at latitude of about $60^{\circ}$ taking the pupil as the North Pole. The needle should be directed towards the center of the eyeball. The fluid comes out slowly because of its viscosity. Gentle aspiration will usually yield 2-3 $\mathrm{ml}$ of vitreous humor. Once the sample has been collected the syringe should be detached from the needle, leaving the needle in place. A volume of water or physiological saline equal to the amount of vitreous humor removed should be slowly injected into the eye to achieve cosmetic restoration. The preservative used is sodium fluoride.

\section{Cerebrospinal fluid}

The cerebrospinal fluid sample is rarely required for toxicological analysis. If needed it should be collected by cisternal puncture. It is difficult to collect CSF at medico legal autopsy by conventional lumbar puncture. It is relatively easier to obtain by cisternal puncture. With the neck flexed, palpate the atlanto- occipital membrane in the midline and, using a needle and syringe, gently introduce a disposable spinal needle through the skin at that point, directing the needle towards the bridge of the nose. As the atlanto occipital membrane is punctured at a depth of approximately $2 \mathrm{~cm}$, loss of resistance will be felt following which CSF can be aspirated. It should be collected in a $30 \mathrm{ml}$ screw capped plastic or glass container. The CSF sample has to be preserved in sodium fluoride.

\section{Other body fluids}

In cases where blood and urine are not available other available body fluids like pericardial ${ }^{14}$ andsynovial fluids ${ }^{15}$ can be used for toxicological analysis like alcohol.

\section{BIOLOGICAL TISSUES}

\section{Liver}

Body tissues are often used for toxicological analysis. Liver is the most important tissue because it concentrates many substances. It can contain large number of drugs and metabolites and may in some difficult cases help establish whether acute or chronic toxicity has occurred. Ideally the part of the liver retained should be fresh unfixed, taken from the periphery of right lobe, away from the stomach, major vessels and gall bladder. A minimum of $100 \mathrm{gm}$. is sufficient for toxicological analysis.

\section{Stomach contents}

The other routinely preserved viscera are stomach and small intestine with its contents and kidney. The sample is useful when drugs have been taken orally as the concentrations will be many times higher than in other fluids. It can also be helpful to determine the amount of drug present in stomach if blood concentration is difficult to interpret. The stomach should be ligated on both ends (esophagus and pylorus) and dissected out. Then the greater curvature should be opened up, so that, the contents directly pour onto the wide mouthed jar. About $30 \mathrm{~cm}$ of small intestine are preserved with the contents. One half of each kidney is preserved. The stomach and intestine with its contents are preserved in one bottle.

\section{Other tissues}

Other tissue samples may be useful for investigating 
Volume 1, Number 2, July 2019

deaths where volatile substances e.g. solvents or gases, are implicated. Brain, fat tissue, lung and kidney are the most useful. Ideally a wet unfixed tissue should be collected into separate glass containers. In case of lung, the sample has to be collected from the apex ofthe lung. The whole lung may have to be preserved in case of solvent abuse or volatile substance poisoning. After opening the thorax, the lung is mobilized and the main bronchus tied off tightly with a string ligature. The hilum is then divided and the lung placed immediately into a nylon bag (prevents the volatile in the sample from escaping) which is sealed and sent as soon as possible to the laboratory.

\section{Bone and Muscle tissue}

In case of decomposed, exhumed, burnt or skeletonized body it becomes difficult and challenging due to absence of blood or scarcity of solid tissues. But whatever remains are available we have to collect all the relevant samples though it may not be the routine sample. If bones ${ }^{10}$ are available the whole long bone should to becollected and preserved. It has to be dried in normal temperature and sealed in plastic bag. Bone marrow samples may be useful in drug identification (qualitative and also quantitative) in cases where all soft tissue has degenerated. The skeletal muscle is also useful for toxicological analysis. A 100 gm. muscle tissue (preferably quadriceps muscle ) has to be preserved in saturated solution of common salt in a plastic or glass container.

\section{Hair and Nail}

Hair and nails are useful samples for analyzing chronic poison (heavy metals) or drug of abuse (opioids). These should be sent if chronic poisoning is suspected, particularly to distinguish between episodic or continuous exposure or for those poisons which may have already been eliminated from the body by the time of death. Hair should be plucked from the scalp with the entire root, shaft and tip. About $500 \mathrm{~g}(20-30$ hairs $)$ of hair should be collected and laid aligned by rolling into a clean plastic or foil sheet with an indication of the scalp ends on the attached label. The whole nail from one toe or fingers can be lifted and collected in a plastic packet.

\section{Maggots}

In decomposed body, if maggots ${ }^{9,16}$ are present 20 gms of maggots can be collected in a plastic or glass container with saturated common salt as the preservative. If drugs or intoxicants are detected they could only have originated from tissues upon which the larvae were feeding. However, the correlations between the level in the larvae and the human have not been established. It only provides qualitative information about drug use.

\section{Injection sites or snake bite}

In case of death due to injection of drugs or suspected snake bite the sample from the injection site has to be preserved. The skin sample with the underneath muscle tissue around the injection site area must be preserved along with a control sample of similar composition from the opposite normal site in saturated solution of common salt

\section{Tablets, powders and syringes}

These samples should be packed with care and any needle protected by a suitable Shield to avoid injury. These items may be particularly useful in deaths in medical personal or drug addicts who may use agents which are difficult to detect once they have entered the body. The use of disposable, hard plastic or glass containers are recommended for preservation. The plastic containers (especially of polypropylene) are increasingly used and have the advantage of not smashing when dropped and also much lighter. The ideal samples are best sent in their original state without adding any preservative in a refrigerated storage (40C) within few hours. But generally, it is not possible to send in this ideal state due to lack of good autopsy facilities, cold storage facilities, quick transport arrangements, legal formalities and quick forensic laboratory services. It usually gets delayed. Therefore, sample has to be put in ideal preservatives to provide optimal conditions till they reach the laboratory. The specimens are generally preserved at $4^{\circ} \mathrm{C}$ during the time until they are analyzed. For long term storage it has to be kept in freezer $\left(-10^{\circ} \mathrm{C}\right)$ until analyzed and disposed of. The most commonly used preservative for viscera tissues are saturated solution of common salt. It is the most easily available, cheap and effective preservative. It is important that the solution should be prepare using pure sodium chloride in distilled water to avoid any contaminants. The other option is rectified spirit $(90 \%$ ethanol) except in cases of poisoning due to alcohol, chloral hydrate, chloroform, phenol, formaldehyde, ether, and phosphorus. In acid or alkali poisoning rectified spirit is the prescribed preservative. The blood for toxicological analysis has to be preserved in $\mathrm{Na}$ Fat the concentration of $10 \mathrm{mg} / \mathrm{ml}$ of blood and potassium oxalate, $30 \mathrm{mg} / 10$ $\mathrm{ml}$ of blood. Fluoride should be added to urine, vitreous humor if alcohol estimations are required.

\section{Forwarding Samples}

All samples should be properly sealed and labeled with the deceased's name, postmortem number, nature of sample, collection site, preservative used, date and time of collection. Particular attention should be paid to the packaging of samples to avoid loss during transport, and to comply with health and safety regulations. It should 
be protected by the use of tamper-evident seals around the lids, and accompanied by an intact chain of custody record. It should be handed over to the Investigating officer after obtaining proper receipt.

The following documents should be enclosed along with the samples ${ }^{4}$ :

I. Name, address and phone number of forensic pathologist and investigating Officer.

II. Circumstances of death and details of drugs thought to be implicated.

III. Past medical history including current or recent prescription medication.

IV. Details of emergency hospital treatment and medication given.

V. Copy of forensic pathologist report if available.

\section{Conclusion}

The samples collected during the postmortem may not yield the expected normal results. However much useful information can be obtained by the thoughtful analysis of samples obtained at postmortem examination and the interpretation of results obtained. Most drugs and poisons including alcohol shows variation in concentration ${ }^{5-8}$ in blood according to the time of specimen collected after death, choice of specimen site, methods of sampling and the volume of blood collected. The blood specimens taken from central sites e.g. heart tends to give particularly high value for most of the analysts. It is particularly important that blood should not be milked from the limbs as this process can engender significant changes in the concentration of critical analysis in the expressed blood. The most consistent quantitative findings are obtained from blood taken from the femoral vein, which is the recommended site for specimen collection. Because of the very great variations ${ }^{12}$ in the concentration of drugs in blood samples taken from different sites, it is important that sample collection is standardized, so that the results obtained can be meaningfully interpreted by comparison with the databases that are being developed incorporating the results of the analysis of samples of blood collected by a uniform technique at postmortem examinations.

\section{References}

1. Walter C. McCurdy. Postmortem specimen collection. Forensic Sci Int. 1987; 35: 61-65.

2. Guidline for poison control, WHO, Geneva,1997: 64-65.

3. Peter White. Crime scene to court: The essentials of forensic sciences. 1 Edn. Royal society of chemistry, Cambridge,U.K, 1998: 232-253.

4. Laboratory guideline, The Medical toxicology unit, Guys and St. Thomas hospital, NHS Trust, London, England.

5. Plueckhahn VD. The evaluation of autopsy blood alcohol levels. Med Sci Law.1968; 8: 168-176.

6. Prouty RW and Anderson WH. The forensic implications of site and temporal influences on postmortem blood-drug concentrations. J Forensic Sci. 1990; 35:243.

7. Jones Gr, Puuder DJ. Site dependence of drug concentrations in postmortem blood-a case study. J Anal Toxicol. 1987; 11: 184-190.

8. O Neal CL and Poklis A. Postmortem production of ethanol and factors which influence interpretation: a critical review. Am J Forensic Med Pathol. 1996; 17: 8-20.

9. Pouuder JD. Forensic entomotoxicology. J Forensic Sci. 1991; 31: 469-472.

10. Noguchi TT, Nakamma GR and Griesemer EC. Drug analysis of skeletonizing remains. J Fornsic Sci. 1978;23: 490-492.

11. Baker RC. In Cravey, R.H and Baselt RC. Introduction to forensic toxicology,1st Edn, Biomedical publication, Davis: CA, 1981: 142-150.

12. Julian Burton and Guy Rutty. The hospital autopsy. 2nd Ed, Arnold, NewDelhi, 2001: 126-133.

13. Bryan Ballantyne, Timothy Marrs and Tore Syversen. General and Applied Toxicology. 2nd Ed, Macmillan, London,1999: 1495-1496.

14. Moriya F and Hashimoto Y. Pericardial fluid as an alternative specimen to blood for postmortem toxicological analysis. LegMed. 1999; 1 (2): 86-94.

15. Oshima T, Kondo T, Sato Y and Takayasu T. Postmortem alcohol analysisof the synovial fluid and its availability inMedicolegal practices. Forensic Sci Int.1997; 10 (90): 131-8.

16. M. Lee Geoff and Wayne D Ford. Entomotoxicology - A new area for forensic investigation. Am J ForMedPathol. 1994; 15(1): 51-57. 